\title{
Crise no mercado de ativos: um modelo pós-keynesiano *
}

\author{
Guilherme Ricardo dos Santos Souza e Silva ${ }^{* *}$ \\ Marcelo Curado ${ }^{* * *}$
}

\begin{abstract}
Resumo
A ocorrência de bruscas elevações/contrações nos preços dos ativos financeiros se constitui num fenômeno recorrente ao longo do desenvolvimento do capitalismo. Para a teoria pós-keynesiana, a própria natureza dos mercados financeiros e o seu funcionamento tendem a causar crises, sem a necessidade de um elemento exógeno. Harvey (2010) apresenta um modelo esquemático que explica as causas endógenas das crises financeiras, englobando os mercados de crédito, de ativos financeiros e de câmbio. No presente artigo apresentamos uma formalização do modelo de Harvey com o intuito de analisar as crises causadas por distorções nos mercados de ativos financeiros. O modelo apresenta uma contribuição no sentido de formalizar as relações entre o comportamento especulativo, o humor dos agentes e o seu estado de confiança. O modelo também trata da relação entre os preços dos ativos e a economia real, considerando uma relação de realimentação entre ambos. Os resultados estão completamente alinhados com as proposições de Keynes e dos pós-keynesianos a respeito da precificação de ativos e de crises nesses mercados.
\end{abstract}

Palavras-chave: Keynes; Mercados de ativos financeiros; Crises financeiras; Macroeconomia; Economia pós-keynesiana

\section{Abstract \\ Speculative bubbles in the asset market: the influence of optimism and the level of confidence in a post- keynesian model}

The incidence of sharp rises/falls in financial asset prices is a recurrent event in capitalism history. For Post Keynesian theory, the very nature of financial markets tends to be the cause of financial crises, and not some exogenous incident. Harvey (2010) presents a schematic model that explains the endogenous causes of financial crises, involving the credit market, financial assets and foreign currencies. In this paper, we present a formal mathematical model based on Harvey's work to analyze financial crises caused by distortions in asset markets. The model presents a contribution in order to formalize the relations between speculation, agents' humor and their level of confidence. The model also deals with the relationship between asset prices and the real economy, considering their mutual feedback. The results are completely in alignment with Keynes and Post Keynesian propositions about financial crises and asset markets.

Keywords: Keynes; Asset markets; Financial crises; Macroeconomics; Post-Keynesian economics. JEL E3, G1, G12.

* Artigo recebido em 13 de novembro de 2014 e aprovado em 24 de janeiro de 2016.

** Professor do Setor de Educação Profissional e Tecnológica da Universidade Federal do Paraná (UFPR), Curitiba, PR, Brasil. E-mail: guilherme.fdg@uol.com.br.

**** Professor do Departamento Economia da Universidade Federal do Paraná / Professor do Programa de PósGraduação em Desenvolvimento Econômico (PPGDE/UFPR). Bolsista Produtividade em Pesquisa do Conselho Nacional de Desenvolvimento Científico e Tecnológico (CNPq), Curitiba, PR, Brasil. E-mail: mlcurado@gmail.com. 


\section{Introdução}

A ocorrência de bruscas elevações/contrações nos preços dos ativos financeiros se constitui num fenômeno recorrente ao longo do desenvolvimento do capitalismo. Bordo (2003) apresenta evidências empíricas de crises financeiras ocorridas nos mercados acionários do Reino Unido e dos Estados Unidos entre 1800 e 1945. Episódios anteriores como a Mania das Tulipas ${ }^{1}$ na Holanda e a South Sea Bubble $^{2}$ no Reino Unido também estão associados ao comportamento especulativo dos agentes.

A ocorrência de flutuações nos preços dos ativos no período do Pós-Guerra, especificamente nos preços das ações, é ainda mais reveladora de seu caráter sistemático. Estudo realizado pelo FMI em 2003 para um conjunto de 19 países industrializados entre 1959 e 2003 revela a ocorrência de 52 quedas acentuadas e persistentes no mercado de ações. A existência de uma elevada correlação entre a deflação no preço dos ativos e a ocorrência de um processo recessivo é outro resultado destacado pelo estudo.

A crise das empresas "ponto com" em 2000 e a recente crise financeira global de 2008 não podem ser entendidas, portanto, como fenômenos pontuais. Pelo contrário, são evidências adicionais de que as flutuações nos preços dos ativos não são fenômenos isolados no sistema econômico, mas sim recorrentes na história recente do capitalismo.

É justamente este caráter recorrente, fruto da operação normal dos mercados, a principal limitação da abordagem da teoria convencional, especialmente em relação aos modelos de bolhas especulativas racionais, para explicar as flutuações nos preços dos ativos, já que as bolhas surgem como um fenômeno exógeno ao funcionamento do sistema econômico (Blanchard; Watson, 1982; Artus, 1995) ${ }^{3}$. Visão radicalmente distinta é encontrada na literatura pós-keynesiana, já que desde os trabalhos originais de Keynes a ocorrência de flutuações nos preços dos ativos é entendida como um fenômeno decorrente do funcionamento normal dos mercados de ativos num contexto de incerteza ${ }^{4}$.

A tendência recorrente dos episódios de crises financeiras é examinada do ponto de vista histórico por Kindleberger e Aliber (2005), que também procuram identificar as características comuns das crises. Os autores debatem a relação entre episódios históricos "únicos" e a tentativa da teoria econômica em generalizar os

(1) Dash (2001) apresenta detalhes sobre o episódio ocorrido na Holanda.

(2) Sobre a South Sea Bubble, Carswell (1960) faz um relato histórico minucioso.

(3) A crítica ao caráter exógeno das crises geradas pela literatura de bolhas especulativas racionais é realizada, entre outros, por Oreiro (2003) e Curado (2006).

(4) Este resultado pode ser encontrado na leitura especialmente dos capítulos 12 e 17 da Teoria Geral de Keynes. 
eventos econômicos, buscando padrões e relações válidas sob quaisquer circunstâncias. Consequentemente, para os autores, a utilização de modelos teóricos pode ser útil para uma melhor compreensão das crises, contudo deve-se ter em mente as limitações de modelos gerais que não observam as peculiaridades da análise histórica.

Em 2010, John Harvey publicou no Journal of Post Keynesian Economics o artigo intitulado: "Modeling financial crises: a schematic approach". O trabalho apresenta uma síntese ${ }^{5}$ das interpretações pós-keynesianas sobre as crises financeiras, com atenção especial para as contribuições originais de Keynes e Minsky. A principal contribuição do trabalho de Harvey (2010) é a elaboração de um modelo esquemático que permite sintetizar os principais elementos da teoria póskeynesiana sobre crises financeiras.

De fato, o modelo esquemático apresentado por Harvey facilita a interpretação das causas que levam a crises financeiras, mas não possibilita a avaliação das relações entre as variáveis envolvidas. Os modelos matemáticos teóricos, por outro lado, possibilitam uma avaliação baseada em hipóteses iniciais e desdobramentos lógicos que levam a um entendimento das relações entre as variáveis endógenas do sistema em análise. Deve-se ressaltar, entretanto, que os modelos matemáticos teóricos em Economia são extremamente limitados, pois precisam simplificar a complexa realidade econômica. Nesse sentido, os modelos explicam apenas um recorte da realidade, e a sua capacidade de elucidação de questões do mundo real depende essencialmente das hipóteses formuladas ${ }^{6}$ e da escolha adequada de quais serão as variáveis endógenas e, portanto, explicadas do sistema.

A partir dessas considerações, este artigo pretende contribuir para o avanço da teoria pós-keynesiana na discussão, com foco na precificação dos ativos financeiros num contexto de incerteza e no qual, portanto, o estado de confiança e o humor dos agentes desempenham um papel chave na definição das expectativas sobre o futuro da economia. Objetivamente, construímos um modelo teórico formal baseado no esquemático elaborado por Harvey (2010) sobre as crises nos mercados de ativos.

(5) Em seu artigo, Harvey apresenta inicialmente o ciclo de investimento em bens de capital e separadamente as crises nos mercados de crédito, de ativos financeiros e de câmbio. Posteriormente o autor sintetiza esses elementos em um diagrama esquemático completo que resume parte relevante da contribuição pós-keynesiana para o entendimento das crises financeiras.

(6) Em Davidson (2009, p. 41) encontra-se uma discussão a respeito da relevância na realidade das suposições em modelos matemáticos: [...]Yet economist Robert Lucas has boasted that the axioms underlying classical economics are "artificial, abstract, patently unreal." But like Samuelson, Lucas insists such unreal assumptions are the only scientific method of doing economics. [...]The rationale underlying this argument is that these unrealistic assumptions make the problem more tractable. With the aid of a computer, the analyst can then predict the future. Never mind that the prediction might be disastrously wrong. 
Para alcançar tal objetivo, o artigo encontra-se organizado da seguinte forma: Após esta breve introdução, a próxima seção apresenta um resumo das ideias centrais de Harvey sobre as crises nos mercados de ativos. Na segunda e terceira seções desenvolve-se o modelo teórico formal e em seguida, na quarta parte, é discutida a dinâmica do modelo. A quinta seção expõe a relação entre a dinâmica observada e a teoria pós-keynesiana. Finalmente, apresentam-se as considerações finais do trabalho.

\section{Crise no mercado de ativos: a abordagem esquemática de Harvey (2010)}

Harvey (2010) discute as causas das crises financeiras, incluindo além daquelas geradas por estruturas de endividamento cada vez mais frágeis, conforme Minsky $(1982,1986)$, as crises geradas pelo mercado de ativos financeiros ${ }^{7}$ e pelo mercado de câmbio. O presente trabalho, tal como apresentado na introdução, tem como objetivo central desenvolver um modelo teórico formal a partir do esquema elaborado por Harvey (2010) para explicar o papel desempenhado pelas crises nos mercados de ações para a ocorrência de crises financeiras ${ }^{8}$.

O ponto de partida de Harvey (2010) para analisar as crises nos mercados de ativos é estabelecer uma relação direta entre o comportamento do Produto Interno Bruto (PIB) e a lucratividade do setor real da economia. A elevação da lucratividade do setor real da economia tende a promover um "impulso inicial" sobre os preços dos ativos no mercado financeiro.

Cabe destacar aqui, no entanto, que a literatura pós-keynesiana apresenta diversos exemplos de crises financeiras geradas endogenamente sem a necessidade de um impulso inicial externo. A hipótese da fragilidade financeira de Minsky (1986), por exemplo, considera a transição para estruturas de endividamento cada vez mais frágeis a partir do próprio funcionamento do sistema econômico. Ainda assim, Minsky discute o impacto de períodos relativamente tranquilos de crescimento sobre a ocorrência de crises financeiras:

The way in which a speculative boom emerges and how an unstable crisis-prone financial and economic system develops are of particular importance in any description of the economic process that is relevant for this economy. Instability emerges as a period of relative tranquil growth is transformed into a speculative boom (Minsky, 1986, p.193).

No modelo aqui proposto, contudo, estamos nos baseando principalmente na contribuição de Harvey (2010), que apresenta a crise no mercado de ativos

(7) $\mathrm{O}$ modelo trata de ativos financeiros similares às ações de firmas produtivas, isto é, títulos representativos de propriedade de empresas com direito a recebimento de dividendos.

(8) As discussões sobre o papel das estruturas de endividamento e dos mercados de câmbio para as crises não serão realizadas, tendo em vista o foco nas crises dos mercados de ativos financeiros. 
financeiros gerada a partir de um impulso inicial que eleva a lucratividade do setor real da economia (causada por um aumento no nível de produto).

O foco de Harvey é demonstrar que é da natureza do próprio sistema a tendência de que os preços dos ativos amplifiquem variações ocorridas na economia real, desde que estejam presentes as condições psicológicas (otimismo e confiança) necessárias para tal. Não obstante, expectativas exuberantes e profecias autorrealizáveis podem gerar crises financeiras mesmo sem uma contrapartida de melhoria (impulso inicial) na economia real.

O cenário de otimismo sobre a lucratividade do setor real e a elevação dos preços dos ativos financeiros tendem, em conjunto, a provocar uma ampliação na lucratividade esperada dos ativos financeiros, elemento que retroalimenta novas elevações nos preços dos ativos financeiros. Neste momento, passa a ocorrer um descolamento entre a lucratividade do lado real da economia e a lucratividade esperada dos ativos financeiros, criando o que Harvey denomina de "ponto de tensão". A Figura 1 apresenta o esquemático apresentado por Harvey (2010) sobre o tema:

Figura 1

Asset-market crisis (Crise nos Mercados de Ativos)

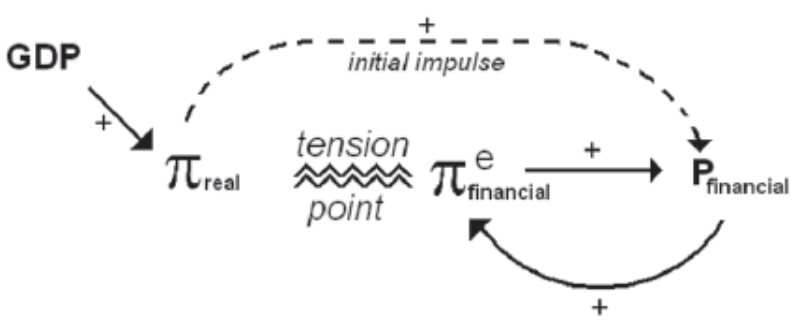

Fonte: Harvey (2010).

Alguns aspectos merecem destaque sobre a abordagem esquemática proposta por Harvey:

i) O esquema, como o autor reconhece ao longo de todo trabalho, não traz para a discussão elementos novos sobre a crise no mercado de ativos. Pelo contrário, trata-se apenas de uma apresentação sintética de elementos amplamente reconhecidos pela literatura pós-keynesiana. Parte substantiva dos argumentos pode ser encontrada nas contribuições originais de Keynes (1936) sobre o tema;

ii) A abordagem esquemática apresenta de forma objetiva alguns elementos essenciais da contribuição pós-keynesiana sobre o tema, mas em especial merece destaque, tal como enfatizado entre outros por Keynes (1936) e Davidson $(1978,2002)$ que as crises nos mercados de ativos decorrem da 
atividade normal dos agentes econômicos num contexto de incerteza e no qual o estado de confiança desempenha um papel central na formação das expectativas dos agentes sobre o futuro.

\section{0 modelo: A influência do produto sobre o preço dos ativos}

Nesta seção será elaborado um modelo formal para a explicação das flutuações nos preços dos ativos baseado no esquema proposto por Harvey (2010). $\mathrm{Na}$ literatura convencional ${ }^{9}$ em geral, os preços dos ativos financeiros (ações) são obtidos através da determinação do valor fundamental do ativo. $\mathrm{O}$ valor fundamental de um ativo é obtido trazendo-se a valor presente o fluxo de dividendos futuros esperado devido à posse do ativo, descontado pela taxa de juros básica da economia. Sargent (1987), por exemplo, em seu modelo keynesiano, considera que o valor nominal das ações é obtido a partir do valor fundamental:

$$
V(t)=\int_{t}^{\infty} d(s) e^{-r(s-t)} d s
$$

onde $V(t)$ é o valor nominal das ações no instante $t, d(s)$ é o fluxo de dividendos das empresas no instante $s$ e $r$ é a taxa de juros utilizada para descontar os fluxos de dividendos futuros.

Não obstante, no capítulo 12 da "Teoria Geral", onde é discutido o Estado da Expectativa a Longo Prazo, Keynes é consideravelmente cético ao considerar a capacidade dos agentes econômicos em determinar o valor fundamental de um ativo:

The outstanding fact is the extreme precariousness of the basis of knowledge on which our estimates of prospective yield have to be made. Our knowledge of the factors which will govern the yield of an investment some years hence is usually very slight and often negligible (Keynes, 1936, p.96).

Ao analisar o comportamento dos investidores no mercado financeiro, Keynes destaca que em muitos casos os agentes estão mais preocupados em antecipar a psicologia do mercado do que em determinar o valor fundamental do ativo:

Thus the professional investor is forced to concern himself with the anticipation of impending changes, in the news or in the atmosphere, of the kind by which experience shows that the mass psychology of the market is most influenced[...]This battle of wits to anticipate the basis of conventional valuation a few months hence, rather than the prospective yield of an investment over a long term of years, does not even require gulls amongst the public to

(9) A tarefa de classificar as contribuições em escolas ou correntes de pensamento é árdua e sujeita a simplificações, dado o elevado grau de heterogeneidade entre os autores. Cientes disso, consideramos como literatura convencional os autores que se baseiam na hipótese de expectativas racionais e na hipótese de mercados financeiros eficientes. 
feed the maws of the professional; - it can be played by professionals amongst themselves. Nor is it necessary that anyone should keep his simple faith in the conventional basis of valuation having any genuine long-term validity (Keynes, 1936, p. 99, grifo nosso).

Dessa forma, o modelo proposto a seguir considera que o preço dos ativos não é obtido somente a partir de seu valor fundamental, mas sofre importante influência de atividades especulativas e expectativas de valorização nos preços dos próprios ativos financeiros. Como veremos adiante, o modelo demonstra que a valorização esperada das ações em si pode ser substancialmente maior do que a expectativa de ampliação nos lucros (dividendos) distribuídos pelas empresas, como consequência da possibilidade de ganhos de capital via especulação.

Assim, o modelo parte da hipótese ${ }^{10}$ de que existe uma relação igual e direta entre a variação percentual da lucratividade efetiva das firmas e as variações percentuais no produto. A equação (1) apresenta este ponto:

$$
\text { (1) } \frac{\Delta \pi_{r}}{\pi_{r 0}}=\frac{\Delta Y}{Y_{0}}
$$

onde: $\frac{\Delta \pi_{r}}{\pi_{r 0}}$ (variação percentual da lucratividade efetiva das firmas, ou $\Delta \% \pi_{r}$ ); $\frac{\Delta Y}{Y_{0}}$ (variação percentual do GDP, ou $\Delta \% Y$ )

Seguindo o referencial teórico pós-keynesiano apresentado por Harvey (2010), assume-se que a variação no preço dos ativos $\left(\Delta P_{f}\right)$ depende de dois componentes:

(i) Da variação na lucratividade efetiva das firmas, que corresponde ao aumento dos dividendos distribuídos aos proprietários dos ativos. Essa parte corresponde à variação no "valor fundamental" das ações, que é obtida trazendo-se a valor presente o fluxo esperado de dividendos futuros. Nesse caso uma dada ampliação percentual nos dividendos distribuídos gera um aumento percentual equivalente no preço das ações.

(ii) Da variação na expectativa de lucratividade dos próprios ativos financeiros, que corresponde à possibilidade de ganhos de capital devido à especulação. O impacto dessa variação depende de $\gamma$, que é uma função do estado de confiança $(S C)$ dos agentes. O modelo considera que $\gamma$ depende do estado de confiança porque os agentes só tendem a transferir uma melhora na expectativa de lucratividade dos ativos para o preço dos referidos ativos se houver um elevado grau de confiança nessa expectativa. Keynes (1936)

(10) Considerando que os lucros são um dos componentes da renda nacional pela ótica da renda, uma ampliação no nível de renda gera um incremento nos lucros. Contudo, como alguns autores pós-keynesianos (por exemplo Kalecki) discutem a distribuição da renda entre lucros e salários, consideramos por hipótese que os lucros aumentam na mesma proporção que o produto. 
destaca no capítulo 12 da "Teoria Geral" que os agentes, ao fazerem suas previsões, avaliam qual o grau de confiança que têm naquela previsão. Em momentos de elevada incerteza, as previsões, ainda que otimistas, podem ser descartadas pelos agentes em função do estado de confiança deteriorado.

Formalmente, estes elementos são apresentados na equação (2):

$$
\text { (2) } \frac{\Delta P_{f}}{P_{f 0}}=\frac{\Delta \pi_{r}}{\pi_{r 0}}+\gamma(S C) \frac{\Delta \pi_{f}^{e}}{\pi_{f 0}^{e}}
$$

onde: $\frac{\Delta \pi_{f}^{e}}{\pi_{f 0}^{e}}$ (variação percentual da lucratividade esperada dos ativos financeiros, ou $\left.\Delta \% \pi_{f}^{e}\right) \mathrm{e}$

$\frac{\Delta P_{f}}{P_{f 0}}$ (variação percentual do preço dos ativos, ou $\Delta \% P_{f}$ ).

Finalmente, o modelo assume que a variação na expectativa de lucratividade dos ativos financeiros depende da variação nos preços dos próprios ativos financeiros, tal como apresentado em (3). O impacto dessa variação depende de $\theta$, que é uma função do estado de confiança dos agentes $(S C)$ e do humor $(H)$, isto é do otimismo/pessimismo em relação ao futuro. O modelo considera que $\theta$, ao contrário de $\gamma$ que depende somente do Estado de Confiança, depende do Estado de Confiança e do Humor dos agentes. Isso porque um aumento no preço dos ativos só terá impacto sobre a expectativa de lucratividade se os agentes estiverem otimistas em relação ao futuro da economia. Além disso, os agentes precisam acreditar que esse otimismo é confiável, isto é, o Estado de Confiança precisa ser elevado.

Se, por exemplo, os agentes estiverem otimistas, mas não tiverem elevada confiança na previsão, um aumento no preço dos ativos não será suficiente para causar uma ampliação da expectativa de lucratividade futura. Existe muita dúvida sobre o futuro e consequentemente as expectativas tendem a permanecer como estão. Por outro lado, se o Estado de Confiança for elevado, mas se os agentes não estão otimistas, a elevação hoje no preço dos ativos não será capaz de afetar positivamente a expectativa de rentabilidade futura. Isso ocorre porque os agentes tendem a acreditar que a elevação atual no preço dos ativos não continuará no futuro, já que é esperada uma redução na atividade econômica.

$$
\text { (3) } \frac{\Delta \pi_{f}^{e}}{\pi_{f 0}^{e}}=\theta(S C, H) \frac{\Delta P_{f}}{P_{f 0}}
$$

Assume-se, portanto, que um aumento hoje no preço das ações emitidas por uma firma pode causar, sob determinadas condições, uma melhora na expectativa de lucro que a posse desses ativos financeiros venha a gerar no futuro. O impacto de um aumento no preço dos ativos sobre a melhora na expectativa de lucros futuros em função de sua posse depende não apenas de previsões otimistas, mas também do 
grau de confiança dos agentes nessas previsões. Substituindo a equação (3) na equação (2), temos:

$$
\text { (4) } \frac{\Delta P_{f}}{P_{f 0}}=\frac{1}{[1-\gamma(S C) \cdot \theta(S C, H)]} \cdot \frac{\Delta \pi_{r}}{\pi_{r 0}}
$$

Finalmente, substituindo (1) em (4), temos:

$$
\begin{gathered}
\text { (5) } \Delta P_{f}=\frac{1}{[1-\gamma(S C) \theta(S C, H)]} \frac{P_{f 0}}{Y_{0}} \Delta Y \quad \mathrm{e} \\
\text { (6) } \frac{\Delta \pi_{f}^{e}}{\pi_{f 0}^{e}}=\frac{\theta(S C, H)}{[1-\gamma(S C) \cdot \theta(S C, H)]} \frac{\Delta Y}{Y_{0}}
\end{gathered}
$$

Assim a partir da equação (5) define-se o impacto de uma ampliação no nível de produto sobre o preço dos ativos financeiros (ações) das firmas. Os parâmetros da equação (5) podem ser descritos da seguinte forma. O parâmetro $\gamma(S C)$ capta o impacto de variações na expectativa de lucratividade dos ativos financeiros sobre os preços atuais desses ativos. $\gamma(S C)$ tem um grau de subjetividade elevado, e seu valor está ligado ao estado de confiança (State of Confidence) com que os participantes do mercado financeiro fazem suas previsões. Apesar do Estado de Confiança ser uma variável subjetiva e incapaz de mensuração direta, o parâmetro $\gamma(S C)$ pode receber um valor numérico a depender do Estado de Confiança médio dos agentes econômicos. De fato, com um estado de confiança extremamente favorável, os agentes acreditam que um aumento na expectativa de lucratividade dos ativos possa ser integralmente transferido para o preço do ativo (pois a expectativa é "confiável"). Nessa situação $\gamma(S C)$ seria igual a um.

Por outro lado, em uma situação de ceticismo e incerteza dos agentes quanto à possibilidade de ganhos especulativos (ou um estado de confiança deteriorado), $\gamma(S C)$ seria igual a zero, indicando que os agentes não repassam a melhora na expectativa para o preço dos ativos, pois a desconfiança é muito grande e expectativas não são suficientes para aumentar efetivamente o preço dos ativos no presente. Assim:

$$
\begin{cases}\gamma(S C)=1, & \text { Estado de Confiança extremamente elevado } \\ \gamma(S C)=0, & \text { Estado de Confiança muito deteriorado } \\ 0<\gamma(S C)<1, & \text { para as situações intermediárias }\end{cases}
$$

O parâmetro $\theta(S C, H)$ capta o impacto de aumentos nos preços dos ativos hoje sobre a sua expectativa de lucratividade futura. Assim como no caso de $\gamma(\mathrm{SC})$, $\theta$ depende do estado de confiança dos agentes na economia. De fato, o estado de confiança é fundamental para que os agentes acreditem em suas previsões, e dessa forma efetivamente transformem o aumento nos preços atuais em expectativas de 
lucro futuros. Além disso, $\theta$ também depende do otimismo/pessimismo (Humor) quanto ao futuro da economia, pois se trata de uma transferência de variações atuais nos preços de um ativo para a expectativa de rentabilidades futuras.

Assim, $\theta(S C, H)$ é igual a um quando o estado de confiança é de plena certeza e quando os agentes são muito otimistas. Por outro lado, $\theta(S C, H)$ é igual a zero caso o estado de confiança esteja deteriorado ou se os agentes forem pessimistas quanto ao futuro. Dessa forma uma ampliação no preço do ativo hoje não seria transferida para sua expectativa de rentabilidade futura. Assim:

$\begin{cases}\theta(S C, H)=1, & \text { Estado de Confiança muito elevado e agentes muito otimistas } \\ \theta(S C, H)=0, & \text { Estado de Confiança muito deteriorado ou agentes pessimistas } \\ 0<\theta(S C, H)<1, & \text { para as situações intermediárias }\end{cases}$

O que determina o estado de confiança $(S C)$ e o humor $(H)$ dos agentes? Evidentemente essas variáveis tem um grau de subjetividade muito elevado e dependem de uma grande quantidade de fatores, alguns dos quais sequer podem ser mensurados. Entre esses fatores podemos considerar inclusive fenômenos totalmente aleatórios e extrínsecos ao sistema econômico, como as manchas solares ${ }^{11}$, citadas no artigo de Cass e Shell (1983). O estado de confiança está associado com a crença dos agentes nas suas próprias previsões sobre o futuro, o que depende de outros fatores, exógenos aos considerados no modelo.

Até esse ponto nossa discussão teve foco no impacto que alterações no nível real de produto da economia causam sobre os ativos financeiros emitidos pelas firmas, destacando-se fundamentalmente que a magnitude desse impacto está essencialmente ligada ao Estado de Confiança e ao Humor dos agentes.

Contudo, é importante destacar que além do nível de produto real, uma variável relevante para a determinação do preço dos ativos é a taxa de juros. A taxa de juros influencia os preços dos ativos principalmente pelo seu impacto ao se descontar o fluxo esperado de dividendos futuros para o valor presente (componente (i) da equação (2)). Considerando um fluxo de dividendos constantes e com duração infinita, o valor presente desse fluxo é dado por:

$$
P_{f}=\sum_{n=1}^{\infty} \frac{d}{(1+i)^{n}}
$$

onde $d$ é o valor do dividendo e $i$ é a taxa de juros. Esta é a soma de uma P.G. infinita de razão $\frac{1}{(1+i)}$. Dessa forma o valor presente do fluxo perpétuo de dividendos é dado por:

(11) Manchas Solares (Sunspots). Em Do sunspots matter? (Cass; Shell, 1983), os autores discutem a influência de fatores totalmente alheios à economia nas decisões dos agentes econômicos. 


$$
P_{f}=\frac{d}{i}
$$

Assim, o impacto de variações na taxa de juros sobre o preço dos ativos financeiros é dado por:

$$
\text { (7) } \frac{\Delta P_{f}}{P_{f 0}}=-\frac{\Delta i}{i_{1}} \text { ou } \Delta P_{f}=-\frac{P_{f 0}}{i_{1}} \Delta i
$$

Dessa forma podemos incorporar o impacto de flutuações na taxa de juros sobre o preço dos ativos financeiros, complementando a equação (5):

$$
\text { (8) } \Delta P_{f}=\frac{1}{[1-\gamma(S C) \theta(S C, H)]} \frac{P_{f 0}}{Y_{0}} \Delta Y-\frac{P_{f 0}}{i_{1}} \Delta i
$$

Ou considerando as variações como diferenciais:

$$
\left(8^{\prime}\right) d P_{f}=P_{f 0}\left(\frac{1}{[1-\gamma(S C) \theta(S C, H)] Y_{0}} d Y-\frac{1}{i_{1}} d i\right)
$$

\section{0 modelo: preço dos ativos e economia real}

Na seção anterior foi dado foco ao impacto de variações no nível de produto real sobre o preço dos ativos financeiros (ações de firmas produtivas). Nessa seção, complementarmente, será discutido o impacto de variações no preço dos ativos financeiros sobre a economia real. Considerando por simplicidade uma economia fechada, temos o produto definido a partir da ótica da demanda como:

$$
\text { (9) } Y=C+I+G
$$

Como estamos interessados nos impactos das variações nos componentes do produto, tomamos o diferencial total de (9):

$$
\left(9^{\prime}\right) d Y=d C+d I+d G
$$

A equação (9') mostra que incrementos no nível de consumo, de investimento ou de gastos do governo se traduzirão em incrementos no nível de produto da economia. Essa situação é válida caso o nível de produto se encontre abaixo do produto de pleno emprego, uma vez que esses três componentes apenas ampliam a demanda agregada no curto prazo. As funções que representam os componentes da demanda agregada: consumo, investimento e gastos do governo são definidas a seguir.

Um aumento no preço das ações das firmas produtivas tende a aumentar a propensão ao consumo, especialmente em uma economia com "mentalidade acionista”. Essa ideia é proposta por Keynes (1936, XXII, p. 319):

With a 'stock-minded' public as in the United States to-day, a rising stockmarket may be an almost essential condition of a satisfactory propensity to consume; and this circumstance, generally overlooked until lately, obviously 
serves to aggravate still further the depressing effect of a decline in the marginal efficiency of capital.

Consideramos que a propensão a consumir não cresce indefinidamente, pois os agentes tendem a manter uma proporção mínima (maior do que zero) da sua renda disponível para poupança. Partindo dessas considerações, a função consumo é dada por:

$$
\text { (10) } C=C\left(Y_{d}, P_{f}\right)
$$

Sendo que: $\frac{\partial C}{\partial Y_{d}}>0 ; \frac{\partial C}{\partial P_{f}}>0 ; \frac{\partial^{2} C}{\partial P_{f}^{2}}<0$.

Isto é, o nível de consumo cresce na medida em que cresce a renda disponível e o preço dos ativos. Contudo, na medida em que o preço dos ativos aumenta, menor é o seu impacto sobre o consumo.

Para a função investimento consideramos inicialmente as relações entre investimento e preço das ações discutida por Davidson $(2002$, p.107) que enfatiza o impacto dos preços das ações das firmas sobre o investimento produtivo:

If the spot price of titles to capital goods is high relative to the flow supply (or production) price for real capital so that the market value of equities exceeds the replacement value of the underlying capital goods (that is, the valuation ratio exceeds unity), then entrepreneurs will find it cheaper to order new equipment rather than attempt to gain control over the flow of services from existing capital goods via the merger and acquisition purchases of secondhand equities.

Minsky (1986) discute o investimento produtivo e a sua relação com os preços de oferta e demanda dos bens de capital. O preço de demanda dos bens de capital, segundo Minsky (1986, p.208), pode ser aproximado pelo valor de mercado dos ativos de capital de uma empresa, em uma economia com uma bolsa de valores atuante:

In a corporate capitalist economy with a stock exchange, the market's valuation of a firm's capital assets and market positions substitutes for the price of capital assets. This market valuation is the sum of the market value of the firm's common stocks and debts minus the value of financial assets the firms owns. This valuation varies with the course of stock market. A stock market boom leads to a higher implicit market value of the underlying capital assets of the economy; conversely, a fall in the stock market lowers the implicit value.

O preço de oferta de produção de bens de capital, para Minsky, depende da força de trabalho, das taxas salariais e das taxas de juros, assim como das técnicas incorporadas ao estoque de bens de capital para a produção de investimento. Seguindo a linha teórica proposta por Minsky e Davidson, o investimento no modelo 
será definido como uma função da relação entre o preço dos ativos financeiros $\left(P_{f}\right)$ e o preço de oferta dos bens de capital $\left(P_{K}\right)$.

$$
\text { (11) } I=I\left(P_{f}, P_{K}\right)
$$

Sendo que ampliações no preço dos ativos financeiros estimulam os investimentos $\left(\frac{\partial I}{\partial P_{f}}>0\right)$, mas esse estímulo tende a se reduzir à medida que o preço dos ativos se eleva $\left(\frac{\partial^{2} I}{\partial P_{f}^{2}}<0\right)$. Por outro lado, ampliações no preço de oferta dos bens de capital tendem a deprimir os investimentos em ativos físicos $\left(\frac{\partial I}{\partial P_{K}}<0\right)$, já que com preços maiores a expectativa de retorno desses ativos é menor.

Conforme discutido na seção anterior, as variações no preço das ações dependem de variações no produto $\left(\frac{\partial P_{f}}{\partial Y}>0\right)$ e de variações na taxa de juros $\left(\frac{\partial P_{f}}{\partial i}<\right.$ $0)$. As variações no preço de oferta dos bens de capital dependem de um grande conjunto de variáveis, algumas das quais não discutidas nesse modelo, como a taxa salarial, a produtividade do trabalho, o nível tecnológico e o nível de preços dos bens da economia. Contudo, uma variável relevante endógena ao modelo que influencia o preço de oferta dos bens de capital é a taxa de juros. Elevações na taxa de juros tendem a encarecer os novos bens de capital produzidos, visto que os recursos financeiros necessários para a produção se tornam mais caros. Assim:

(12) $P_{K}=P_{K}(\Omega, i)$

Sendo que $\frac{\partial P_{K}}{\partial i}>0$ e $\Omega$ representa o conjunto de variáveis exteriores ao modelo que influenciam o preço de oferta dos ativos de capital. Como $\frac{\partial P_{f}}{\partial i}<0$ e $\frac{\partial P_{K}}{\partial i}>0$ segue que $\frac{\partial I}{\partial i}<0$, isto é, elevações na taxa de juros desestimulam os investimentos em bens de capital. Finalmente os gastos do governo e a tributação são dados de forma exógena ao modelo. Tomando o diferencial total das equações (10) e (11) e considerando a renda disponível como $\mathrm{Y}_{\mathrm{d}}=\mathrm{Y}-\mathrm{T}$ :

$$
\begin{gathered}
\left(10^{\prime}\right) d C=\frac{\partial C}{\partial Y_{d}} d(Y-T)+\frac{\partial C}{\partial P_{f}} d P_{f} \\
\left(11^{\prime}\right) d I=\frac{\partial I}{\partial P_{f}} d P_{f}+\frac{\partial I}{\partial P_{K}} d P_{K}
\end{gathered}
$$

Substituindo (10') e (11') em (9') e após os algebrismos:

$$
\text { (13) } d Y=\frac{\left(\frac{\partial I}{\partial P_{K}}\right) d P_{K}+\left(\frac{\partial C}{\partial P_{f}}+\frac{\partial I}{\partial P_{f}}\right) d P_{f}+d G-\frac{\partial C}{\partial Y_{d}} d T}{1-\left(\frac{\partial C}{\partial Y_{d}}\right)}
$$

A equação (13) afirma que uma variação no produto ocorre quando há uma alteração em uma das variáveis que influenciam os componentes da demanda agregada: preço 
dos ativos financeiros (que afetam o consumo e investimento), o preço de oferta dos bens de capital (que afeta o investimento) ou ainda diretamente via gastos do governo e tributação. Indiretamente a taxa de juros, que influencia o preço dos ativos financeiros e o preço de oferta dos bens de capital, também pode afetar a demanda agregada.

Assim, a partir de (13) é possível determinar o impacto de uma variação no preço dos ativos financeiros sobre o nível de produto. A figura 2 apresenta a relação de realimentação entre variações no nível de produto e alterações no preço dos ativos. De fato, uma variação inicial exógena no nível de produto $\left(\Delta Y_{0}\right)$, causará, conforme a equação (5), uma alteração no preço dos ativos $\left(\Delta P_{f 0}\right)$. Essa variação no preço dos ativos causa, via flutuação do consumo e do investimento, uma nova modificação no nível de produto $\left(\Delta \mathrm{Y}_{1}\right)$. Novamente, a variação no produto causará uma alteração no preço dos ativos $\left(\Delta P_{f 1}\right)$, e assim sucessivamente. Esse processo continua até o ponto em que a propensão a consumir se aproxima de seu valor máximo e enquanto a variação no preço dos ativos influenciar o investimento. A partir desse ponto cessa o impacto do preço dos ativos sobre o produto e o ciclo termina.

Figura 2

Processo de realimentação entre preço dos ativos e produto

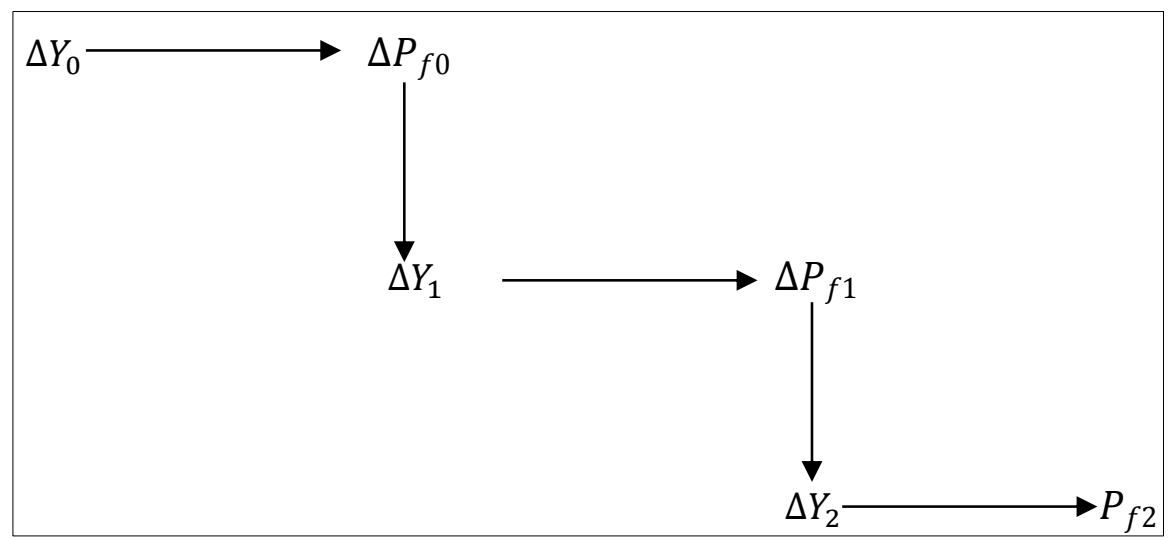

Fonte: Elaboração própria.

A partir da lógica da Figura 2, e das equações (5) e (13), considerando as diferenciais como variações e alterações apenas em $P_{f}$, isto é $d i=d G=d T=$ 0 , temos:

(5a) $\Delta P_{f 0}=\frac{1}{[1-\gamma(S C) \cdot \theta(S C, H)]} \frac{P_{f 0}}{Y_{0}} \Delta Y_{0} \quad$ onde, $\Delta P_{f 0}=P_{f 1}-P_{f 0}, \Delta Y_{0}=Y_{1}-Y_{0}$

Em que (5a) representa a ampliação no preço dos ativos financeiros decorrente do crescimento exógeno no nível de produto. 
(13a) $\Delta Y_{1}=\frac{\left(\frac{\partial C}{\partial P_{f}}+\frac{\partial I}{\partial P_{f}}\right)}{\left(1-\frac{\partial C}{\partial Y_{d}}\right)} \Delta P_{f 0}$

Em que (13a) representa o crescimento no nível de produto real como consequência da flutuação do consumo e do investimento, causados pela ampliação anterior no preço dos ativos. Seguindo o mesmo raciocínio $\Delta P_{f 1}, \Delta Y_{2}$ e $\Delta P_{f 2}$ podem ser obtidos, representando as ampliações subsequentes nos preços das ações e nos níveis de produto real. As ampliações de produto como consequência do aumento no preço das ações, no entanto, ocorrem somente se o produto está abaixo do produto de pleno emprego $^{12}$. Assim, o aumento total no preço dos ativos e o aumento total no nível de produto após $n$ períodos é dado por:

$$
\begin{gathered}
\Delta P_{f}=\Delta P_{f 0}+\Delta P_{f 1}+\Delta P_{f 2}+\Delta P_{f 3}+\cdots+\Delta P_{f n} \\
\Delta Y=\Delta Y_{0}+\Delta Y_{1}+\Delta Y_{2}+\Delta Y_{3}+\cdots+\Delta Y_{n}
\end{gathered}
$$

Como $\left[\frac{\left(\frac{\partial C}{\partial P_{f}}+\frac{\partial I}{\partial P_{f}}\right)}{\left(1-\frac{\partial C}{\partial Y_{d}}\right)}\right]$ tende a zero à medida que $P_{f}$ cresce (pois o consumo e o investimento apresentam retornos marginais decrescentes, isto é $\frac{\partial^{2} C}{\partial P_{f}{ }^{2}}<0 e \frac{\partial^{2} I}{\partial P_{f}{ }^{2}}<$ $0), \Delta P_{f}$ e $\Delta Y$ serão convergentes, desde que: $[1-\gamma(S C) \theta(S C, H)] \neq 0$.

Se a condição de convergência for válida o ciclo se encerra com $\Delta P_{f}$ e $\Delta Y$ convergindo para valores finitos. Se a condição não se verificar o preço dos ativos cresce infinitamente logo na primeira iteração.

Cabe destacar que o resultado acima foi obtido considerando-se $d i=d G=$ $d T=0$. Contudo, de acordo com a equação (8'), a taxa de juros exerce influência sobre o preço das ações, tendendo a reduzir o impacto positivo de uma ampliação no nível de produto. Assim, a taxa de juros pode trabalhar como um elemento amortecedor das elevações nos preços dos ativos causadas por excesso de otimismo e por um estado de confiança muito favorável. Dessa forma, ampliações na taxa de juros durante o processo $(d i>0)$ tendem a encerrar o ciclo da figura 2 mais rapidamente (pois reduzem o preço dos ativos e o nível de investimento), isto é:

$$
\begin{gathered}
\frac{\partial P_{f}}{\partial i}=-\frac{P_{f 0}}{i_{1}}<0 \\
\frac{\partial I}{\partial i}=\frac{\partial I}{\partial P_{f}} \frac{\partial P_{f}}{\partial i}+\frac{\partial I}{\partial P_{K}} \frac{\partial P_{K}}{\partial i}<0
\end{gathered}
$$

(12) Caso o produto já esteja em seu nível de pleno emprego, os preços dos bens tenderão a subir, fazendo com que a ampliação real do preço dos ativos seja zero. Nesse caso os níveis de consumo e investimento não são estimulados, pois não houve crescimento real no preço dos ativos e teríamos $\Delta \mathrm{Y}=0$, encerrando o ciclo. 
Pois $\frac{\partial I}{\partial P_{f}}>0, \frac{\partial P_{f}}{\partial i}<0, \frac{\partial I}{\partial P_{K}}<0, \frac{\partial P_{K}}{\partial i}>0$

\section{A dinâmica do modelo}

Nesta seção analisaremos possíveis resultados que o modelo apresenta sob diferentes condições dos parâmetros definidos na seção anterior. A Figura 3 apresenta, a partir da equação (5), o impacto de uma ampliação do nível de produto sobre o preço dos ativos para diferentes configurações de $\gamma(S C)$ e $\theta(S C, H)$.

Figura 3

Comportamento de $\Delta \% P_{f}$ e $\Delta \% Y$ para diferentes $\gamma(\mathrm{SC})$ e $\theta(S C, H)$

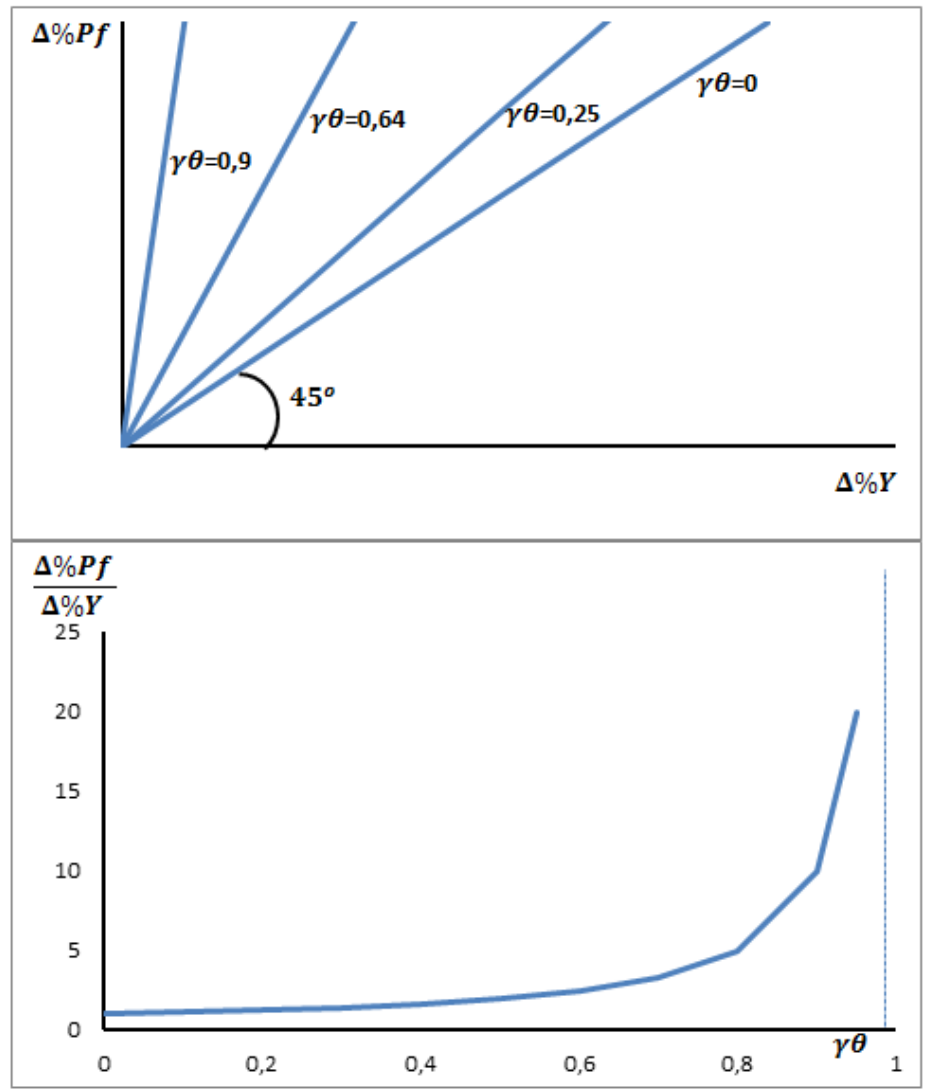

Fonte: Elaboração própria.

Observa-se que se $\gamma(S C)=0$ e $\theta(S C, H)=0$, a variação percentual no preço dos ativos é exatamente igual à variação percentual no produto (ângulo de $45^{\circ}$ ). Esta seria a situação na qual os participantes do mercado financeiro estão com o estado de confiança (SC) deteriorado, isto é com muita incerteza em relação ao futuro, e com o humor $(\mathrm{H})$ pessimista. Nesse caso, apenas aumentos nos lucros efetivos das firmas são capazes de gerar aumento nos preços dos ativos. 
Na medida em que $\gamma(\mathrm{SC})$ e $\theta(S C, H)$ crescem observa-se o descolamento entre a ampliação do produto e o aumento no preço dos ativos. Quanto maior o valor do produto $(\gamma \theta)$ maior é a inclinação da reta $\Delta P_{f} x \Delta Y$, ou maior é a razão $\frac{\Delta \% \boldsymbol{P} f}{\Delta \% \boldsymbol{Y}}$. No limite, se $\gamma(\mathrm{SC})=1$ e $\theta(S C, H)=1$, a reta seria vertical e uma ampliação no nível de produto levaria a um aumento infinito ${ }^{13}$ no preço dos ativos. $\gamma(\mathrm{SC})=1$ e $\theta(S C, H)=$ 1 representam a situação na qual os agentes tem confiança plena nas suas previsões e são totalmente otimistas quanto ao futuro. De fato, essa é uma situação muito improvável na economia real. O ponto relevante, no entanto, é que quanto maior a confiança dos agentes nas suas previsões e seu o otimismo quanto ao futuro, maior é o descolamento entre a ampliação do nível de produto e o aumento do preço dos ativos.

A partir da Figura 2, observamos que uma ampliação no preço dos ativos leva a um aumento no próximo período do nível de produto, pois se espera uma elevação no consumo e no investimento, conforme a equação (13). Assim, a partir de (13), a figura 4 apresenta o impacto do aumento no preço dos ativos sobre o produto. Observa-se que aumentos nos preços dos ativos ampliarão a demanda agregada (DA), através de aumento de consumo e investimento, mas somente até um determinado ponto, pois $\frac{\partial^{2} C}{\partial P_{f}{ }^{2}}<0 e \frac{\partial^{2} I}{\partial P_{f}{ }^{2}}<0$.

Figura 4

Comportamento de $\Delta Y / \Delta P_{f}$ x $P_{f}$

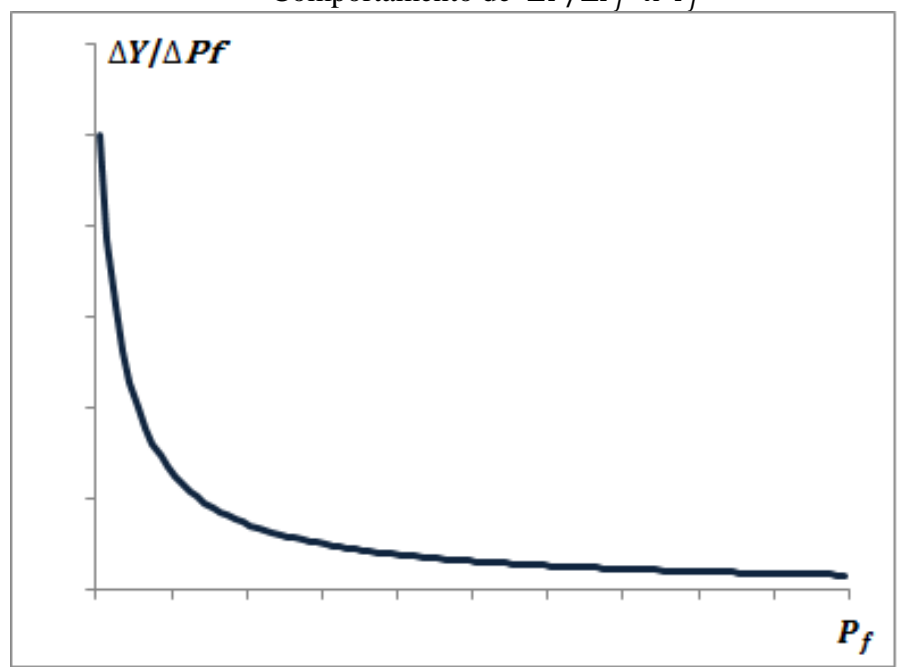

Fonte: Elaboração própria.

(13) Cabe destacar que esta é uma situação limite. De fato, na economia real nunca há $100 \%$ de confiança em uma previsão e os agentes não podem ser completamente otimistas quanto ao futuro. De fato, se $\gamma(\mathrm{SC})$ e $\theta(S C, H)$ fossem igual à unidade o preço das ações tenderia ao infinito logo no primeiro período após a elevação do produto. 
Assim, a partir de um determinado valor de $\boldsymbol{P}_{\boldsymbol{f}}$, praticamente cessa o impacto do aumento no preço dos ativos $\left(\Delta \boldsymbol{P}_{\boldsymbol{f}}\right)$ sobre o nível de produto. $\mathrm{O}$ ciclo apresentado na Figura 2, nessas condições, necessariamente chega ao fim, de forma que o aumento no produto e a ampliação dos preços dos ativos são convergentes (desde que $\gamma(S C) \theta(S C, H) \neq 1$ ).

Quanto maior o otimismo em relação ao futuro da economia e maior a confiança nas previsões e na possibilidade de ganhos especulativos (isto é, $\boldsymbol{\gamma}$ e $\boldsymbol{\theta}$ mais próximos da unidade), maior é o ritmo de expansão do preço dos ativos. Se houver uma transferência da ampliação dos preços dos ativos no presente para a expectativa de ganhos futuros, e se essas expectativas afetam o preço atual, então os preços dos ativos crescem mais rapidamente que o nível de produto. Nesse modelo é a busca por ganhos especulativos, a melhora nas expectativas de lucros futuros e a elevada confiança nas previsões que causam o descolamento entre preço dos ativos e nível de produto real. A Figura 5 apresenta o comportamento temporal do produto e do preço dos ativos, enquanto a Figura 6 mostra o diagrama de fase destas variáveis.

Figura 5

Crescimento do produto e do preço dos ativos no tempo

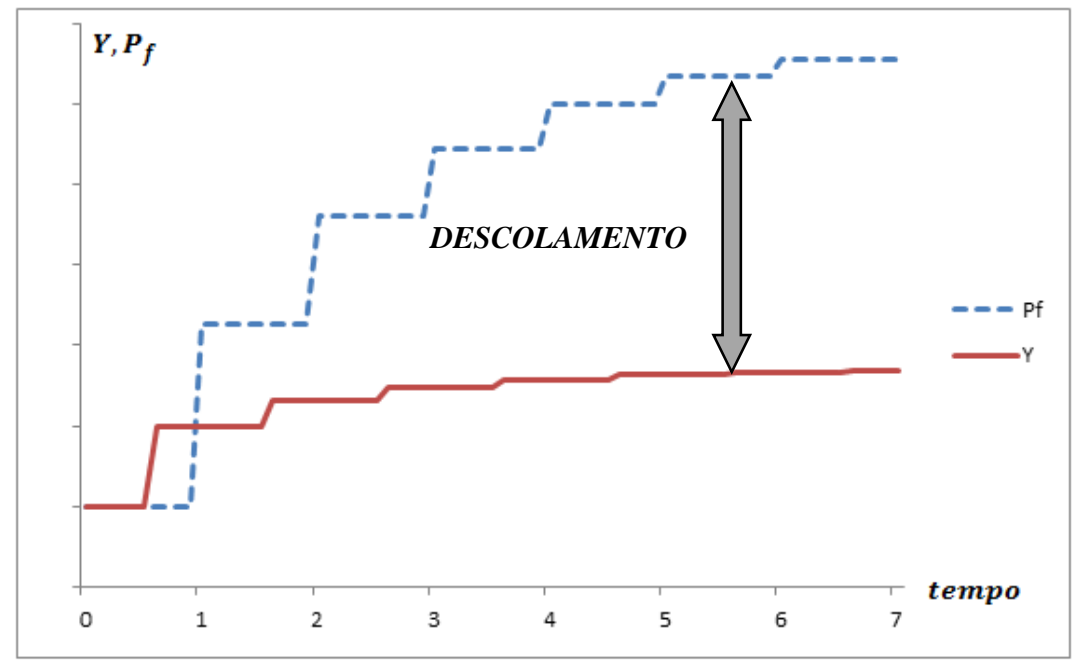

Fonte: Elaboração própria. 
Figura 6

Diagrama de fase do produto e do preço dos ativos

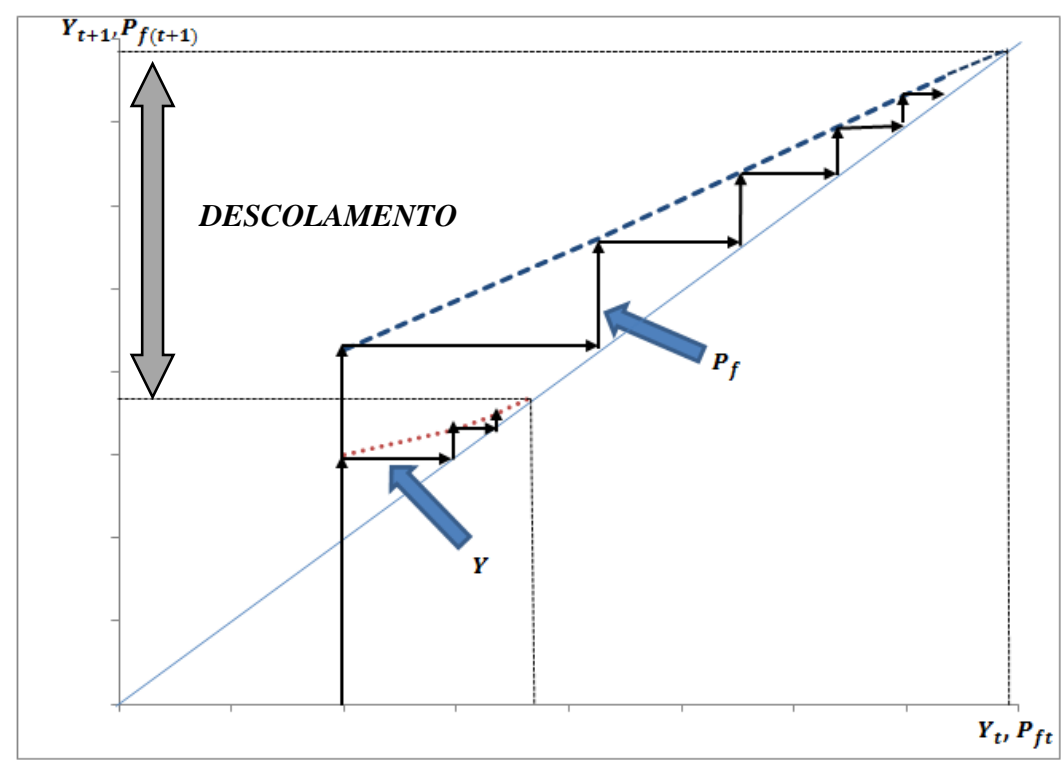

Fonte: Elaboração própria.

O diagrama de fases demonstra o comportamento das variáveis preço de ativos e produto, observando-se a relação entre o valor atual da variável $(\mathrm{t})$ e seu valor no próximo período $(\mathrm{t}+1)$. Verifica-se, a partir do diagrama, que as ampliações nos preços dos ativos tendem a ser maiores do que os aumentos no produto. Isso acontece sempre que a multiplicação $\gamma(S C) \cdot \theta(S C, H)$ for diferente de zero. Quanto mais próximo da unidade for o valor de $\gamma(S C) . \theta(S C, H)$, maior é a diferença entre as magnitudes de crescimento do produto e do preço das ações.

O descolamento entre a variação no produto e no preço dos ativos levará em um dado momento (ponto de ruptura) a uma queda brusca no preço desses ativos. Esse pode ser o gatilho para a ocorrência de uma crise financeira. Ao perceberem que os preços dos ativos estão exageradamente altos, os agentes revisam para baixo suas expectativas. O resultado deste processo é uma queda brusca no preço destes ativos. A determinação do ponto de ruptura é bastante difícil, mas desenvolvimentos da teoria pós-keynesiana associados ao conceito de "convenção" podem auxiliar no entendimento desse fenômeno.

A ideia de convenção, utilizada por Keynes no capítulo 12 da "Teoria Geral", não é definida formalmente e não há um consenso na literatura sobre tal conceito (Dequech, 1999). Possas (1986, p.304), ao referir-se ao comportamento convencional, afirma que: "A solução adotada implicitamente pelos agentes econômicos que possuem riqueza a ser valorizada é, ao invés de eliminar, tentar 
"contornar" a incerteza de suas expectativas pelo recurso a normas de comportamento convencionais".

Segundo Oreiro (2000) a convenção pode ser definida como uma regra coletiva de comportamento, sendo que um requisito básico e indispensável para que um comportamento se torne uma convenção é de que seu uso seja generalizado pelos agentes econômicos. Paula (2006, p. 189) destaca a relação entre convenções e o conhecido "comportamento de manada" (herd behavior) exibido pelos participantes dos mercados financeiros:

Assim, o comportamento dos especuladores pode estar associado a algum tipo de "comportamento de manada", já que sob incerteza um investidor tem incentivo a imitar o comportamento médio dos demais agentes, uma vez que esses podem ter informações que ele não tem e, na pior das hipóteses, é melhor perder conjuntamente do que perder sozinho. Em outras palavras, o comportamento "seguir a maioria" pode ser uma convenção adequada para superar a incerteza sobre o futuro, sobretudo em condições quando a incerteza aumenta o desconhecimento das ações de outros agentes. Este tipo de comportamento pode inclusive gerar "profecias auto-realizadas", o que faz com que as expectativas determinem as trajetórias de preços nos mercados financeiros e cambiais.

Oreiro (2006, p. 318), ao apresentar um modelo pós-keynesiano de bolhas nos preços de ativos, discute a crítica à teoria dos "mercados eficientes" e o impacto do comportamento de manada sobre os mercados financeiros. "Seguir a manada pode ser uma decisão sensata quando o retorno privado ao se adotar um determinado comportamento for uma função crescente do número de agentes que adotam o mesmo comportamento".

Assim, pode-se considerar que enquanto a convenção apontar para a manutenção dos preços dos ativos financeiros em um patamar elevado, poucos investidores deverão se direcionar contra essa convenção. Evidentemente muitos investidores perceberão, em diferentes momentos, que os preços dos ativos estão descolados do nível de atividade real.

No entanto, somente quando a convenção se modificar, é que se instalará o comportamento de venda de ativos de maneira generalizada, derrubando rapidamente as expectativas e determinando o denominado ponto de ruptura. Afinal, de acordo com Keynes (1936), o principal objetivo do especulador não é determinar o valor verdadeiro do ativo financeiro, mas sim antecipar como o mercado precificará esse ativo ${ }^{14}$. Esse ponto é extremamente relevante, pois demonstra a possibilidade de ineficiência na determinação dos preços inerente aos mercados financeiros. De fato, nessa situação, os preços dos ativos podem se manter em um patamar mais elevado do que o indicado pelos "fundamentos", mesmo que muitos

(14) A metáfora do concurso de beleza dos jornais utilizada por Keynes (1936) ilustra esse ponto. 
agentes saibam que esses preços não refletem a "realidade". Keynes (1930 apud Erturk, 2006) destaca essa possibilidade no Tratado da Moeda:

If everyone agrees that securities are worth more, and if everyone is a 'bull' in the sense of preferring securities at a rising price to increasing his savings deposits, there is no limit to the rise in price of securities and no effective check arises from a shortage of money $(\mathrm{CW}, \mathrm{V}, \mathrm{p} .229)$. However, as prices continue to rise, a 'bear' position begins to develop, and that is what can eventually check the rise in prices. ...[I]n proportion as the prevailing opinion comes to seem unreasonable to more cautious people, the 'other view' will tend to develop, with the result of an increase in the 'bear' position ... (CW, V, p. 228229).

Da mesma forma que a ampliação no preço dos ativos gerou um impacto positivo no nível de produto através do aumento na demanda agregada, a queda abrupta no preço dos ativos levará à redução nos níveis de consumo e investimento. Essa redução pode acontecer de forma rápida e intensa, gerando uma situação de recessão econômica a partir do efeito contágio entre mercado financeiro e economia real. Deve-se considerar ainda que uma vez instalada a crise, aumenta o pessimismo e a incerteza em relação ao futuro, o que tende a reduzir ainda mais os investimentos produtivos, visto que a eficiência marginal do capital se reduz. A Figura 7 apresenta graficamente essa questão.

Figura 7

Queda no preço dos ativos e crise financeira

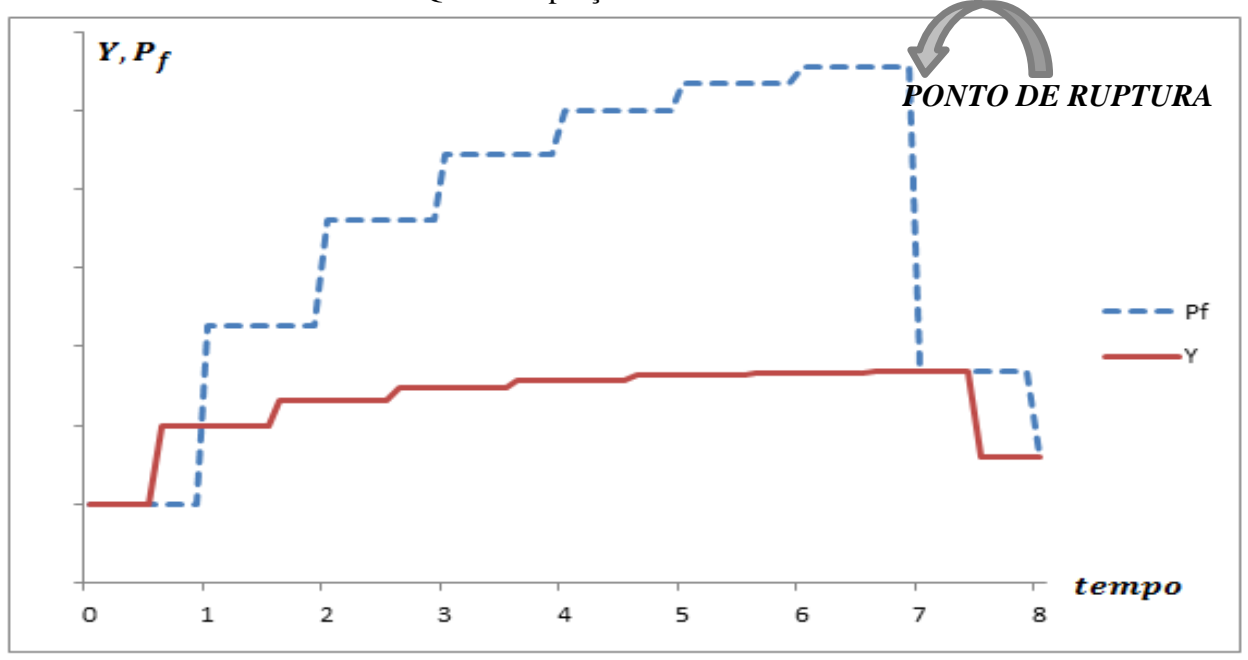

Fonte: Elaboração própria.

A teoria pós-keynesiana, portanto, atribui ao comportamento dos agentes importância fundamental para o entendimento do desenvolvimento e da ruptura das convenções que levaram à formação da bolha especulativa. A teoria das finanças 
comportamentais (behavioral finance) também parte da ideia de que uma melhor compreensão da psicologia do mercado e do comportamento dos agentes é essencial para um entendimento mais profundo dos mercados financeiros e de suas crises. Apesar de não ser considerada parte da teoria "convencional" das finanças, estudiosos das finanças comportamentais tem tido uma posição de destaque nos meios acadêmicos ${ }^{15}$. A abordagem das finanças comportamentais é consideravelmente distinta da teoria pós-keynesiana, mas ambas as correntes criticam fortemente a utilização de agentes representativos racionais e a hipótese dos mercados financeiros eficientes.

Shiller (2000), por exemplo, argumenta que existem sérios riscos na utilização de modelos fortemente baseados na hipótese de mercados financeiros eficientes para a discussão de política econômica. Para o autor, à medida em que o teórico se esforça para ser cada vez mais preciso, tende a se aumentar o risco de que a análise apresente uma visão demasiadamente estreita, a ponto de se tornar irrelevante fora do mundo acadêmico. As evidências apresentadas pelo autor apontam no sentido de que a realidade atual dos mercados de ações está longe de ser um "tubo de ensaio". Se a teoria das finanças almeja se tornar mais útil, os economistas terão que se envolver com os aspectos mais "confusos" da realidade dos mercados.

\section{Avaliação da dinâmica à luz da teoria pós-keynesiana}

Considerações fundamentais para o entendimento do processo avaliado pelo modelo proposto são tratadas na teoria pós-keynesiana. A relevância dos fatores psicológicos nos mercados financeiros é extensamente discutida por Keynes e pelas correntes pós-keynesiana, institucionalista e das finanças comportamentais. Raines e Leathers (2011) discutem as contribuições de Keynes, Davidson e Galbraith no entendimento do funcionamento dos mercados financeiros. Galbraith, em sua teoria das bolhas especulativas, segundo os autores, enfatiza a necessidade psicológica de um estado persistente de confiança e otimismo que leva à construção de "um mundo especulativo de faz de conta". A origem desse estado especulativo ou eufórico é desconhecida, mas os seus efeitos são frequentemente observados.

A teoria pós-keynesiana apresenta um instrumental bastante abrangente e fundamentado na "realidade" dos mercados financeiros, conforme destacado por Raines, McLeod e Leathers (2007), que avaliam o entendimento dos mercados financeiros e a formação de bolhas especulativas segundo a teoria dos mercados racionais e a teoria dos mercados especulativos de Keynes e dos pós-keynesianos. Nesse sentido, os entendimentos distintos das correntes teóricas em relação aos mercados financeiros são baseados em diferentes "visões de mundo" e em

(15) Por exemplo Kahneman e Shiller, ambos agraciados com o Prêmio em Memória de Alfred Nobel. 
pressupostos divergentes, como a ergodicidade versus a não-ergodicidade na economia, ou a liquidez versus a eficiência dos mercados de ativos financeiros.

De fato, para os pós-keynesianos, é pelo fato de a economia ser não-ergódiga que os mercados secundários organizados de ativos existem. Em um mundo de previsão perfeita, os ativos seriam mantidos em carteira por seus rendimentos de longo prazo (Davidson, 1978). Um ponto importante enfatizado pela teoria póskeynesiana é que, no mundo real, os mercados eficientes não são líquidos, enquanto que os mercados líquidos não são eficientes. Dessa forma, a função primária dos mercados financeiros é promover liquidez e não eficiência na formação de preços. Pelo fato de os preços não poderem ser perfeitamente conhecidos em uma economia não-ergódiga, a teoria dos mercados eficientes é inevitavelmente falha (Davidson, 2002).

Na tentativa de compatibilizar os resultados empíricos que evidenciam a formação de bolhas especulativas com a racionalidade dos agentes e a teoria dos mercados eficientes, é proposto o modelo de bolhas especulativas racionais. A teoria parte de uma equação de arbitragem entre ações e um ativo sem risco. Demonstra-se que, mesmo sob o pressuposto de comportamento racional dos agentes, é possível a formação de bolhas especulativas. Oreiro (2003) destaca que em um contexto de equilíbrio geral, por exemplo, em modelos de gerações sobrepostas do tipo Diamond, as bolhas só podem existir se a população é composta por um número finito de agentes com horizonte de planejamento finito. Ainda nesse caso, um requisito para a existência de bolhas é que a economia seja dinamicamente ineficiente ${ }^{16}$ (Blanchard; Fischer, 1989).

A diferenciação entre risco e incerteza é outro ponto fundamental para a compreensão dos mercados financeiros segundo a teoria pós-keynesiana. Risco e incerteza são densamente explorados por Frank H. Knight em seu livro "Risk, Uncertainty and Profit". Knight (1921) define claramente a diferença entre risco e incerteza, sugerindo o uso da palavra incerteza apenas quando nos referimos aos casos em que não é possível a quantificação de probabilidades. Keynes (1921) também já se mostrava sensível à confusão existente entre risco e incerteza mesmo antes da Teoria Geral e do Tratado sobre a Moeda, conforme observamos em seu livro "A treatise on probability".

A teoria pós-keynesiana considera relevante o aprofundamento das questões relativas à incerteza no sentido Knight-Keynes, conforme observado nos trabalhos de Davidson (1978, 2002). Contribuições recentes como Carvalho (1994) e Ferrari e

(16) Em uma economia dinamicamente ineficiente a quantidade de capital acumulada é maior do que a que seria eficiente no sentido de Pareto (Oreiro, 2003). 
Araújo (2000) aprofundam a discussão a respeito dos efeitos da incerteza sobre o comportamento dos agentes e a relação entre caos e incerteza.

Cabe destacar ainda que após a eclosão da crise financeira de 2008, o entendimento mais aprofundado desse tipo de episódio ganhou ainda mais relevância, sendo amplamente discutido por diversas correntes do pensamento econômico. Palley (2009), por exemplo, expande a discussão das crises financeiras para prazos mais longos, argumentando que a corrente pós-keynesiana em geral tem dado ênfase à análise de médio prazo baseada principalmente na análise do ciclo básico de Minsky (Hedge-Especulativo-Ponzi). O artigo então propõe-se a discutir a dimensão de longo prazo implícita no trabalho de Minsky (que o autor denomina "Minsky Super-Cycles"). Enquanto o ciclo básico opera principalmente no nível dos agentes e empresas (destacando a influência dos aspectos psicológicos), o superciclo ocorreria em função de modificações profundas nas instituições, nas convenções de negócios e nas estruturas que governam o mercado. Nesse sentido surgem novas possibilidades de contribuições para o entendimento das crises financeiras baseadas nas teorias heterodoxas, e principalmente na observação dos fenômenos empíricos.

Considerando o foco na "realidade econômica" e na explicação de fatos estilizados, Borio (2012) discute a relação entre os ciclos financeiros e a macroeconomia. O autor destaca a necessidade da utilização de estratégias de modelagem que capturem a essência do funcionamento dos mercados financeiros e seus impactos macroeconômicos, a partir da observação dos fatos estilizados. Ao apresentar ${ }^{17}$ dados relativos aos ciclos financeiros e macroeconômicos, o autor observa a tendência de os ciclos financeiros apresentarem amplitudes consideravelmente maiores que os ciclos reais, conforme mostra a Figura 8.

\section{Figura 8}

Comparação entre os ciclos do PIB e financeiro

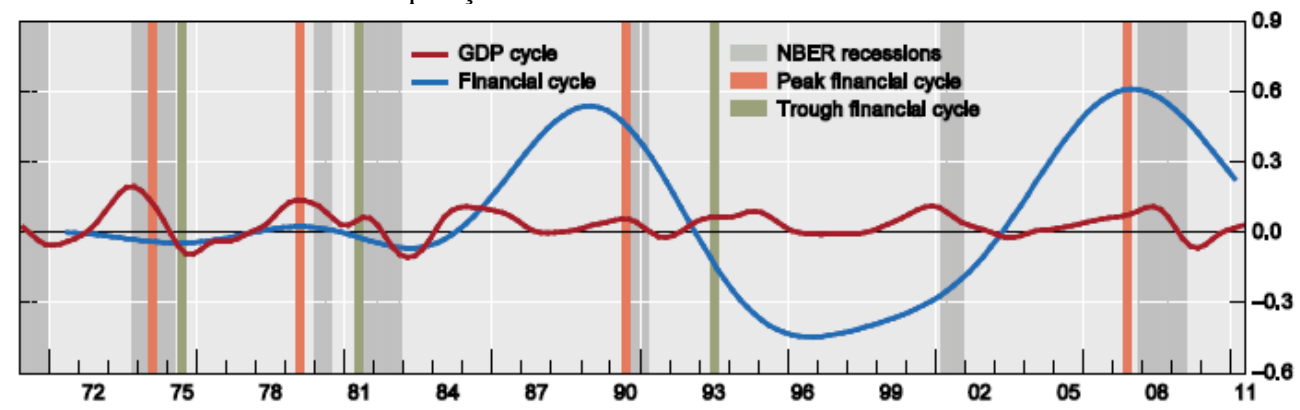

Fonte: Borio (2012), citando Drehmann et al. (2012)

(17) O autor apresenta os dados extraídos de Drehmann et al. (2012). 
Borio, contudo, destaca as dificuldades na própria interpretação dos dados empíricos, iniciando pela inexistência de consenso na definição do que é o ciclo financeiro. Os dados apresentados consideram como ciclo financeiro as interações auto reforçadoras entre as percepções de valor e risco, as atitudes diante do risco e as restrições financeiras, que se transformam em booms seguidos de "busts". Em seguida o autor descreve de forma muito próxima ao presente trabalho os efeitos dessas interações:

These interactions can amplify economic fluctuations and possibly lead to serious financial distress and economic dislocations. This analytical definition is closely tied to the increasingly popular concept of the "procyclicality" of the financial system (Borio, 2012, p. 2).

$\mathrm{O}$ autor conclui que a modelagem analítica capaz de explicar satisfatoriamente as características fundamentais dos mercados financeiros precisa abandonar os processos de formação de expectativas baseados somente em expectativas racionais, considerando a possibilidade da incerteza sistêmica. Para tanto poderiam ser incorporadas percepções de risco e atitudes em relação ao risco que se modificam ao longo do ciclo financeiro. É precisamente esse um dos objetivos buscados pelo modelo apresentado no presente artigo.

\section{Considerações finais}

O presente artigo apresentou uma breve discussão sobre a influência de variáveis "psicológicas" e comportamentais no processo de precificação de ativos, e consequentemente na possibilidade de formação de bolhas especulativas. A partir dessa discussão, foi proposto um modelo formal de inspiração pós-keynesiana, baseado no esquemático elaborado por Harvey (2010). A conclusão, a partir da análise do modelo, é que na presença de agentes que buscam ganhos especulativos em mercados financeiros, a combinação de um estado de confiança favorável com um otimismo generalizado leva ao descolamento entre o nível de produto real e o preço dos ativos financeiros. Tais elementos foram propostos originalmente por Keynes (1936) e extensamente discutidos pela literatura pós-keynesiana, conforme apresentado por Minsky (1986) e Davidson (2002), por exemplo.

O modelo proposto apresenta uma contribuição no sentido de formalizar essas relações e identificar os parâmetros que levam ao descolamento entre a economia real e os preços das ações de empresas. Nesse sentido, o modelo permite a avaliação da interligação bi causal entre o lado produtivo da economia e os preços dos ativos financeiros. Uma vez ocorrido o descolamento, a emergência de uma crise financeira é apenas uma questão de tempo, visto que os agentes em um dado momento revisarão suas expectativas e em conjunto chegarão a um novo consenso sobre o preço dos ativos. Após a queda brusca no preço dos ativos financeiros, tende a ocorrer uma queda no nível de produto real, o que leva eventualmente a uma 
situação de recessão econômica. A discussão sobre os canais de transmissão da crise financeira para a recessão na economia real também faz parte do modelo.

O desenvolvimento de teorias e modelos que se aproximem da "realidade" dos mercados financeiros vem sendo considerado relevante por algumas correntes do pensamento econômico, em especial para que haja uma maior aceitação da teoria fora do campo acadêmico. Nesse sentido o presente trabalho procura, na medida do possível, incorporar elementos não convencionais na modelagem formal, dando destaque ao papel da atividade especulativa e à importância do otimismo e do estado de confiança dos agentes na precificação de ativos financeiros.

\section{Referências bibliográficas}

ARTUS, P. Anomalies sur lês marchés finaciers. Economie Poche. Paris: Economica, 1995.

BLANCHARD, O. J.; FISCHER, S. Lectures in macroeconomics. New York: MIT Press, 1989.

BLANCHARD, O.; WATSON, M. W. Bubbles, rational expectations and financial markets. Cambridge, Massachusetts: National Bureau of Economic Research, 1982. (NBER Working Paper Series, n. 945).

BORDO, M. Stock market crashes, productivity boom busts and recessions: some historical evidence. Washington: International Monetary Fund, 2003. (World Economic Outlook)

BORIO, C. The financial cycle and macroeconomics: what have we learnt? BIS Working Papers No 395, December 2012.

CASS, D.; SHELL, K. Do sunspots matter? Journal of Political Economy, v. 91, n. 2, 1983.

CARSWELL, J. The South Sea Bubble. London: Cresset Press, 1960.

CARVALHO, F. C. Sobre ordem, incerteza e caos em economia. Revista Brasileira de Economia, Rio de Janeiro, v. 48, n. 2, 1994.

CURADO, M. Flutuações nos preços dos ativos: uma comparação entre as bolhas especulativas racionais e a contribuição keynesiana. Economia e Sociedade, Campinas, v. 15, n. 1 (26), 2006.

DASH, M. Tulipomania: the story of the world's most coveted flower and the extraordinary passions it aroused. London: Gollancz, 2001.

DAVIDSON, P. Money and the real world. 2. ed. New York: John Wiley \& Sons, 1978. 
DAVIDSON, P. Financial markets, money and the real world. Cheltenham: Edward Elgar Publishing Limited, 2002.

DAVIDSON, P. The Keynes solution. New York: Palgrave McMillan, 2009.

DEQUECH, D. On some arguments for rationality of conventional behavior under uncertainty. Campinas: Unicamp. IE, 1999. (Texto para Discussão, n. 80).

ERTURK, K. A. Speculation, liquidity preference and monetary circulation. In: ARESTIS, Phillip; SAWYER, Malcolm C. (Ed.). A handbook of alternative monetary economics. 2006.

FERRARI FILHO, F.; ARAÚJO, J. P. Caos, incerteza e teoria pós-keynesiana. Ensaios FEE, Porto Alegre, v. 21, n. 2, p. 163-182, 2000

HARVEY, J. T. Modeling financial crises: a schematic approach. Journal of Post Keynesian Economics, v. 33, n. 1, p. 61-81, Fall 2010.

KEYNES, J. M. The general theory of employment, interest and money. New York: Harcourt, Brace and Company, 1936.

KEYNES, J. M. A treatise on probability. London: Macmillan and Co. Limited, 1921.

KINDLEBERGER, C. P.; ALIBER, R. Z. Manias, panics, and crashes - A history of financial crises. $5^{\text {th }}$ ed. John Wiley, 2005.

KNIGHT, F. (1921). Risk, uncertainty and profit. New York: Sentry Press, 1964

MINSKY, H. Stabilizing an unstable economy. Yale University Press, 1986

OREIRO, J. L. Bolhas racionais, ciclo de preços de ativos e racionalidade limitada: uma avaliação crítica dos modelos de bolhas especulativas. Revista Análise Econômica, Porto Alegre, ano 21, n. 40, 2003.

OREIRO, J. L. Incerteza, comportamento convencional e surpresa potencial. Economica, n.4, p. 111-138, dez. 2000.

OREIRO, J. L. Capital mobility, real exchange rate appreciation, and asset price bubbles in emerging economies: a Post Keynesian macroeconomic model for a small open economy. Journal of Post Keynesian Economics, v. 28, n. 2, p. 317, Winter 2005-2006.

PALLEY, T. I. A theory of Minsky super-cycles and financial crises. Contributions to Political Economy, v. 30, n. 1, p. 31-46, 2011.

PAULA, L. F. R.; Macroeconomia aberta em contexto de globalização: algumas notas em uma perspectiva pós-keynesiana. In: FERRARI FILHO, F. Teoria geral, setenta anos depois: ensaios sobre Keynes e teoria pós-keynesiana. Porto Alegre: Editora da UFRGS, 2006, p. 179-206. 
POSSAS, M. L. Para uma releitura teórica da Teoria Geral. Pesquisa e Planejamento Econômico, Rio de Janeiro, Ipea, p. 295-308, ago. 1986.

RAINES, J. P.; McLEOD, A.; LEATHERS, C. G. Theories of stock prices and the Greenspan-Bernanke doctrine on stock market bubbles. Journal of Post Keynesian Economics, v. 29, n. 3, p. 393-407, Spring 2007.

RAINES, J. P.; LEATHERS, C. G. Behavioral finance and Post KeynesianInstitutionalist theories of financial markets. Journal of Post Keynesian Economics, v. 33, n. 4, p. 539-555, Summer 2011.

SHILLER, R. P. Irrational exuberance. Princeton University Press, 2000. 